JURNALYOGA DAN KESEHATAN

JURUSAN YOGA KESEHATAN

FAKULTAS BRAHMA WIDYA

IHDN DENPASAR
Vol. 3 No. 1 Maret 2020

ISSN : 2621-0185 (Cetak)

http://ejournal.ihdn.ac.id/index.php/jyk

\title{
Pentingnya Laku Semedi Bagi Pemangku dan Pinandhita
}

\author{
Romo Poniman \\ Institut Hindu Dharma Negeri Denpasar \\ email :romoponiman@gmail.com
}

Diterima tanggal 6 November 2019, diseleksi tanggal 5 Desember 2019, dan disetujui tanggal 24 Desember 2019

\section{ABSTRACT}

The highest desirable behavior for the followers of Kejawen is, among others, exercise, exercise which in this case requires a routine training. Having a high mysticism can be more sensitive to feelings in overcoming and accepting conditions. But to have a high level of mysticism requires a special discipline of life and behavior to achieve this situation. In practicing selfdiscipline, a follower of Kejawen should often do Semedi. By meditation in this case it is a special behavior to train oneself to join oneself with Gusti. Before doing Semedi, you should realize the concept of the existence of the Three Realms in the human body. After knowing it, the Semedi training can be carried out to find the peak of success that will eventually be trained to have a sensitive and holy mind so that peace is felt.

\section{Kerwords: Laku semedi, pemangku, pinandhita}

\section{ABSTRAK}

Prilaku tertinggi yang diinginkan bagi pengikut Kejawen diantaranya olahbatin, olahroso yang dalam hal ini membutuhkan suatu pelatihan yang rutin. Dengan memiliki kebatinan yang tinggi maka dapat lebih peka pada rasa dalam mengatasi dan menerima keadaan. Namun untuk memiliki tingkat kebatinan yang tinggi itu diperlukan suatu disiplin hidup dan prilaku khusus guna tercapai keadaan itu. Dalam melatih disiplin diri, maka seorang penganut Kejawen hendaknya sering melakukan Semedi. Oleh semedi dalam hal ini adalah suatu prilaku khusus untuk melatih diri menggabungkan diri pribadi dengan Gustinya. Sebelum melakukan Semedi hendaknya disadari adanya konsep adanya alam Triloka dalam tubuh manusia itu. Setelah mengetahuinya maka latihan Semedi dapat dilakukan hingga menemukan puncak keberhasilan yang pada ujungnya akan terlatih batinnya peka dan suci sehingga kedamaian dirasakannya.

Kata Kunci: Laku semedi, pemangku, pinandhita

\section{PENDAHULUAN}

Manusia dikatakan sebagai mahkluk pribadi sekaligus juga mahkluk sosial. Sebagai mahkluk pribadi maka manusia memiliki kemandirian dalam menentukan nasib dirinya sendiri. Demikian jika memahami yang dimaksud sang Diri, maka manusia yang berpribadi itu mampu 
menempa dirinya menjadi mahkluk yang memiliki mental yang kuat sebelum bergumul dengan komunitas social dilingkungannya. Demikian juga bagi manusia Jawa yang dikenal memiliki budaya Kejawen bahwa mereka memiliki tatacara tersendiri dalam menempa diri pribadinya.

Memahami tentang budaya kejawen maka perlu diketahui bawa budaya menurut Triguna (2008: 33) dalam arti yang luas mencakup; ideologi, filosofi, system nilai, norma, etika, estetika, juga candi, seni tari, seni lukis, bahasa, bangunan, sistem simbol, gambelan, folklore, kearifan lokal, serta secara lebih dinamik mencakup sikap hidup, gaya hidup, dan cara hidup seperti budaya disiplin, budaya kerja, budaya instan dan lain-lain. Manusia sebagai objek utama bagi suatu Agama yang memiliki budaya. Dalam mempertahankan budayanya, masyarakat Jawa memiliki kreatifitas yang fleksibel terhadap pengaruh dari luar. Sehingga kebudayaan Jawa semakin mengalami peningkatannya. Tradisi masyarakat Jawa lebih meningkat pada masa masuknya paham Hindu. Menurut Soekmono (2017: 35-78) yang dimulai dari Kutai Kalimantan sekitar tahun 400 Masehi dan masuk ke daratan Jawa tepatnya di Kerajaan Tarumanagara Jawa Barat sekitar tahun 400-500 Masehi sampai ke wilayah Jawa Timur yaitu mencapai masa kejayaaanya pada berdirinya kerajaan Majapahit sekitar tahun 1293-1528 Masehi. Namun baru pada tahun 1429-1522 dikatakan sebagai masa kelam pengaruh Hindu ditanah jawa akibat kejayaan Majapahit mengalami kemunduran. Kemunduran Hindu di tanah Jawa banyak faktor yang mempengaruhinya.

Seiring perjalanan waktu maka perkembangan kebudayaan Jawa mengalami perubahan itu hingga saat ini terjadi percampuran atau sinkretisme. Hal ini sesuai dengan sifat orang jawa yang terbuka menerima pengaruh darimanapun yang menguntungkan dirinya dalam menjalani kehidupan ini. Maka saat ini bagi penganut budaya Jawa bisa dipengaruhi oleh jawa Asli, Hindu Buddha, Islam, Kristen dan pada akhirnya mendapat sebutan Penganut Kejawen. Dengan demikian Penganut Kejawen adalah mereka yang memiliki prilaku khusus yang tidak terpengaruh oleh agama tertentu saja. Melainkan mereka yang memiliki kemandirian dalam olah kebatinan guna memantabkan kepribadiannya.

Bagi penganut Kejawen sebagai dasar prilaku yang paling utama jika mereka sudah menemukan Jatidirinya. Untuk mengetahui jatidirinya itu, maka ada beberapa langkah yang harus dijalankan sehingga tercapai apa yang dikehendakinya. Oleh karena itu dalam penulisan ini perlu diketahui secara mendalam tentang bagaimana cara menemukan jatidiri pengikut Kejawen. Selanjutnya bagaimana prilaku yang harus dijalankan untuk mengetahui jatidiri manusia bagi penganut Kejawen. Maka untuk mengetahui jawaban tersebut perlu dipaparkan secara menyeluruh agar tercapai penemuan jatidiri bagi penganut Kejawen sebagai berikut;

\section{PEMBAHASAN}


Untuk menemukan Jatidiri bagi Penganut Kejawen maka terlebih dahulu perlu diketahui beberapa pengetahuan tentang Jagad Cilik atau Buana Alit yaitu badan manusia itu sendiri. Bahwa dalam tubuh manusia ada 3 alam, namun manusia sendiri tidak menyadari akan keberadaan alam tersebut. Sama seperti raga ini, manusiapun tidak merasa bahwa kita memliki raga ini. Banyak manusia yang belum menyadari keberadaan ketiga alam tersebut. Bahwa karena keberadaannya memerlukan kesadaran ilmu, maka dalam hal ini perlu dijelaskan tentang ketiga alam tersebut dalam Badan Manusia itu. Adapun Ke tiga alam tersebut adalah:

1. Alam Guru loka Berada di Otak.

2. Alam Indra loka Berada di Hati.

3. Alam Jana loka Berada di Kelamin.

Guna mengetahui pemahaman atas ketiga alam tersebut maka perlu diketahui keberadaannya dalam tubuh manusia. Hal ini tidak terlepas karena adanya posisi keadaan diri. Saat manusia tengah berpikir, maka diposisikan pada tengah berada di guru loka, saat manusia merasa sedih, senang, diposisikan berada di indra loka. Ketika kita beraktifitas fisik, diposisikan berada di jana loka. Posisi ketiga alam tersebut harus diyakini terlebih dahulu bagi yang belum memahami. Dengan demikian maka bagi penganut Kejawen dapat masuk pada pemahaman pada tingkatan lebih lanjut.

\subsection{Memahami Badan Pikir}

Pemahanan adanya Badan Pikir sangat diperlukan karena pikiranlah yang mampu mengendalikan kesadaran sebelum masuk pada tataran lebih lanjut. Bekerja dengan menggunakan badan pikir itu dalam bahasa Jawa ada beberapa macam, seperti; Mikir, nggagas, manah, nyuraos, nyipta, ngeling-eling, dan lain sebagainya. Hanya dalam bahasa Indonesia, hal-hal tersebut memang kurang di tegaskan (diuraikan), paling hanya sekedar ; berpikir, mengingat-ingat, mencipta. Oleh karenanya di sini perlu saya sebutkan macam-macam dari badan pikir itu dalam bahasa Jawa sebagai berikut.

1. Mikir

Kata Mikir, dalam bahasa Jawa, itu dilakukan ketika kita tengah; menghitung sesuatu, seperti ; menjumlah, mengurang, membagi dan mengalikan bilangan itu kita harus berpikir. Bagaimana cara menggapai tujuan dan cita-cita, kita juga harus berpikir. Intinya, di dalam menjalani hidup ini kita selalu berpikir, mulai dari bangun tidur hingga kembali mau tidur, kita tidak pernah berhenti berpikir, kecuali suatu hal yang sudah menjadi suatu kebiasaan, kita memang tidak pernah berpikir dan sudah secara langsung dilakukan akibat terbiasa. 
2. Nggagas

Kalimat Nggagas ini sebenarnya juga tidak jauh berbeda dengan kata mikir, tetapi yang disebut menghitung seperti menambah, membagi, mengurangi, mengalikan itu bukan termasuk nggagas sehingga perlu diperdalam lagi misalkan tetang keberadaan Tuhan yang dikatakan Maha Adil, maka ada kalimat nek tak gagas Tuhan itu Adil ya dalam membagi rejeki pada manusia.

\section{Manah (Nggalih)}

Kata Manah untuk memperdalam perlu perumpamaan misalkan adanya Orang yang baru bermain catur, halma, main kartu dan lain sebagainya, tentunya akan berpikir bagaimana supaya bisa menang. Selama kita terpaku dalam permainan itu, kita sampai-sampai jarang berbicara dengan orang sekeliling kita. Karena kita tengah nglimbang-nglimbang, ngonceki, bagaimana caranya supaya kita bisa menang. Ketika saat itu terjadi, jika pikiran kita nggrambyang, tidak wening, tidak konsentrasi, tentu akan mudah di kalahkan, terlebih jika dalam bermain itu kita merasakan suatu perasaan yang tidak enak, muka terasa panas, khawatir, tidak semeleh dan lain sebagainya, maka jangan berharap kita akan menang seperti yang diharapkan semula.

4. Ngeling-eling

Kalimat Ngeling-eling (mengingat-ingat) itu berbeda juga dengan ke tiga hal di atas. Mengingat-ingat itu adalah mencari sesuatu yang terlupa, yang tadinya memang sudah tersimpan di cipta kita. Mengingat-ingat atas kejadian yang pernah dialaminya itulah jika belum ketemu perlu pengingatan secara mendalam yang dinamakan Ngeling-eling.

\section{Nyipta}

Seperti kalimat daya cipta, maka kata Nyipta itu adalah membuat wujud didalam pikiran kita dengan bahan baku yang belum ada (kalaupun ada, bahan tersebut tidak berada di alam nyata). Cipta itu mempunyai daya. Gambar/pemandangan yang indah menimbulkan perasaan senang di batin kita, sebaliknya, gambar yang tidak baik akan menimbulkan perasaan yang tidak enak di dalam batin kita. Oleh karenanya, jaman dahulu jika seorang wanita tengah hamil, di sarankan oleh orang tua orang tua jaman dahulu untuk selalu menatap cengkir gading yang ada gambar Bethara Kamajaya dan Dewi Ratih, agar terpatri di cipta si biyung gambaran-gambaran yang indah-indah, dengan harapan kelak jika jabang bayi terlahir di dunia akan memiliki paras yang indah dan perasaan serta jiwa yang bagus, karena dayaning cipta si biyung ini pasti tumama ke dalam benih si jabang bayi tersebut. Jangankan benih yang sudah terbuahi, benih yang belum dibuahipun sudah ketaman dayaning cipta si biyung atau ibunya. 


\subsection{Laku Semedi Jalan Menemukan Jatidiri}

\section{Puja Semedi}

Sebelum pada posisi Semedi, maka perlu dipahami tentang Puja Semedi. Manungku Puja (Muja Samadhi) itu bagaikan orang konsentrasi, menyatukan daya pikir dan cipta kita hanya untuk muja. Pada saat kita melakukan Puja Samadhi ini kita harus mantheng temenanan yaitu menyatukan pikran secara teguh mateng tak tergoyahkan, tidak boleh menoleh kiri kanan. Jadi benar-benar hanya untuk muja. Prilaku Muja inipun juga hampir sama dengan nyipta, yaitu membuat sesuatu dengan bahan yang sudah ada dengan kekuatan cipta manusia. Kemampuan ini perlu disadari bahwa manusia bisa menciptakan hal ini membuktikan manusia adalah bentuk Jagad Cilik atau Bhuwana Alit.

\section{Manekung}

Prilaku Manekung adalah suatu proses dimana nalar dan rasa makarti secara bersamaan. Untuk lebih jelasnya, mungkin bisa saya gambarkan seperti orang yang tengah menyaksikan pertunjukan wayang kulit, Saat manusia menyaksikan pertunjukan wayang kulit, saking senengnya sampai-sampai kita lupa bahwa wayang yang bergerak kesana kemari dan yang berbicara itu adalah karena ulah sang dalang. Kita begitu terhanyut dengan pertunjukan itu, bahkan kadang kita sampai lupa pula akan keadaan sekeliling kita. Di situ kita hanyut dengan perasaan kita. Tenggelam dalam perasaan kita karena alur cerita dari wayang kulit tersebut. Tidak jarang kita juga ikut merasa sedih, senang, gembira, jengkel dan lain sebagainya. Saat itu seringkali nalar kita tidak bekerja, hanya perasaan yang terhanyut karena alur cerita tersebut. Jika nalar kita ikut makarti, tidak hanya kenyut saja, namun juga nggagas cerita yang tengah berlangsung tersebut seperti ; Benarkah cerita wayang itu dulu benar-benar terjadi. Di manakah letak kerajaan Amarta itu dan lain sebagainya, seperti itulah gambaran dari yang dinamakan manekung, yaitu suatu proses di mana nalar dan rasa makarti secara bersamaan sehingga manusia mampu menyadari dirinya secara khusuk sampai terlupakan dalam kesadarannya sendiri atas peristiwa yang ia alami.

\section{Maneges, Mahas Ing Ngasepi}

Maksud dari kalimat Maneges, mahas ing ngasepi itu maksudnya mirengaken swaraning ngasonya (ngasepi). Jelasnya begini; "Ngasepi" atau "ngasonya" itu artinya: pun sepi, pun nyenyet, anu sing sepi, anu sing nyenyet. Bukan "sepi" nipun, dede "nyenyet" ipun, nanging "anu”-nipun yang sepi. "Anu“-nipun ingkang sepen nyenyet tersebut, oleh karenanya di sebut: ngasepi, ngasonya. Lalu dimanakah letaknya, papan dunungipun pun sepi, pun nyenyet itu tadi maka disinilah perlunya pemahaman bahwa Ngasepi atau ngasonya ini adalah tempat yang jarang di ambah manusia, yaitu telenging samodra, dimana seperti cuplikan kisah Dewa 
Ruci bahwa Werkudara bertapa di situ hingga bertemu dengan Dewa Ruci, yang kesit tan-kena ginrayang, tan kena ginatra, tansah nyamun, tan alit tan agung.

Ngasepi atau ngasonya itu adalah mirengaken yang dumunung di telenging batin kita, bagai Werkudara mendengarkan suara Sang Dewa Ruci. Jika swaraning ngasonya sudah terdengar jelas, Werkudara lantas masuk ke guwa garbane Sang Dewa Ruci (Yudhi: 2012).

\subsection{Tahapan Sebelum Melakukan Semedi}

Untuk mempersiapkan menuju Laku Semedi tidak diperlukan berbagai sarana pendukung yang berupa bahan missal bunga, kemenyan dupa dan sebagainya, namun yang sangat diperlukan hanyalah niat dan tekad. Yang penting adalah tata, titi, teliti, telaten nganti atul. Jadi dilakukan berulang-ulang tanpa bosan hingga menjadi suatu kebiasaan, hingga menjadi suatu rutinitas yg merupakan kebutuhan, Dan pada saatnya nanti, pasti akan 'bertemu'. Namun untuk mencapai puncak Semedi perlu diperhatikan beberapa tahapan berikut ini;

1. Tertata.

Untuk mencapai pada keadaan Cipta maka kita harus di tata. Tidak tumpang tindih, tidak semrawut, acak2an. cipta adalah juga hal yg sangat penting, segalanya yang tertata harus berurutan tidak semrawut dalam pikiran. Itulah kenapa bahwa cipta kita harus di tata. Bahkan dlm memohon sesuatu pun hrs urut. Bukannya pagi samadhi memohon A, B, C ... lalu siangnya ganti C, A, B dan lain sebagainya.

2. Suci.

Keadaan Rasa kita haruslah suci, bersih. Terbebas dari rasa apapun. Rasa takut, benci, susah, senang, cemburu, curiga, sombong, bebaskan dari segala rasa kepemilikan, keinginan dan lain sebagainya. Jadi harus benar-benar bersih dan suci. Tidak terkejut, tidak keheranan dan sebagainya.

3. Lugu.

Adapun yang dimaksud Lugu disini adalah seperti bayi yang tidak punya perasaan takut sumelang dlsb. Bayi jg tdk pernah berprasangka buruk terhadap apapun. Bersih. Letakkan dahulu segala pemahaman yang kita punya tentang ketuhanan, lepaskan semua anggapan yang kita miliki. Lepaskan dulu segala ego. Sehingga benar-benar bersih, Lugu atau Polos.

4. Merdhika.

Istilah Merdhika maksudnya bebas. Bebas dari segala yang membelenggu. Bebas dari panca indra. Selama kemanusiaan kita masih mengikat/membelenggu, maka yang di dalam juga tidak akan kita temui. Semakin kita ngungkungi keterikatan tsb, kita akan semakin 'kehilangan', sebaliknya, semakin kita bisa memerdhekakan, kita akan 'menemukan'. 
Bebas juga dari segala pikiran atau perasaan apapun. Rasa, cipta dan karsanya hanya tertuju ke satu. Yaitu DIA Penguasa Jagad. Krungu ning ora ngrungoake, weruh ning ora nyawang, ngganda ning ora diambu, krasa ning ora di rasaake dlsb. Jadi merdhika, bebas dari segala pengaruh panca indra yang selalu bersama badan manusia.

5. Tenang.

Apabila point 1-4 sudah djalankan, maka tidak adalagi yang perlu kita lakukan. Tinggal satu ini sikap, yaitu Sikap Tenang teguh tak tergoyahkan oleh keadaan apapun. Sikap terakhir inilah yang penting, karena ada beberapa orang yang gelisah bahkan mundur dari kegiatan Semedi jika tidak memiliki ketenangan.

\subsection{Proses Pada Saat Samadhi}

Setelah kita melakukan persiapan diatas, kita tinggal 'meneng'. Ada banyak mantra atau ucapan yang diperolehkan sebelum melakukan Semedi. Hal ini dilakukan sebagai bentuk komunikasi antara alam Jagad Cilik ke dalam Jagad Gede. Dan berikut contoh ucapan dalam bahasa Jawa begini: "Bapa biyung ingkang ngukir jiwa raga kula, kula ngaturaken sembah pangabekti saha nyuwun gunging pangapunten kaliyan nywn pangestu. Jagad bumi alam kabeh, kutu2 walang ataga lan sagung tumitah kang dumadi, apuranen sakabehing luputku lan reksanen uripku. Dhuh Gusti ingkang Murbeng Gesang saha Ingkang Murbeng sih, kula ngaturaken sedaya pejah, gesang, jiwa, raga, nyawa, suksma lan sedaya tanggel jawab kula mugi konjuk wontening Ngarsa Paduka. Lan Sumoggo sedoyo kulo pasrahaken Dumateng Paduko Gustine Manuso Sejagad Triloka" Terus Diam Hening. Tidak meminta atau memohon apapun. Hanya memasrahkan segalanya kepada yang Maha Kuasa.

Selanjutnya sesudah itu, entah dengan rapal atau tidak, terserah yang menjalani, mata melihat ke pucuking grana. Yg dinamakan pucuking grana itu adalah diantara dua alis, bukannya ujung hidung yg di antara dua cuping hidung. Cukup memandang itu dgn rambatan keluar masuknya nafas, merasakan keluar masuknya nafas dari hidung ke paru2. Jd bukan mengkonsentrasikan segalanya ke dada atau mengkonsentrasikan ke pikiran. Bukan. Juga bukan dengan mengosongkan pikiran kita. Semua dalam kesadaran. Sesudah mandeng pucuking grana dan rambatan tali nafas, Lama kelamaan akan terjadi semacam rebat deg. Rebutan kekuasaan antara pikiran dan perasaan. Kadang di pikiran, kadang di perasaan. Jangan memilih dan memilah. Biarkan hal itu terjadi, dan mata tetap mandeng pucuking grana sambil rambatan keluar masuknya nafas. Semakin lama akan terasa semakin luyut, seperti mengantuk, tapi jangan sampai tertidur, karena begitu kita tertidur, gumun, kaget dlsb, 'acara kita batal' sudah. Kita mengulangi lagi dari awal. Setelah sekian lama terjadi rebat deg, semakin luyut, suatu saat kita 
akan mengalami yang dinamakan 'liyep layaping aluyup'. Seperti orang mau tertidur, 'mak liyep'. Tapi sekali lagi tidak boleh sampai tertidur. Pada saat itulah terjadinya 'sumusuping rasa jati', seperti yang digambarkan oleh Sri Paduka Mangkunegara IV dalam Serat Wedatama Pupuh Pangkur pada teks ke 13;

Tan samar pamoring suksma,

Sinuksmaya winahya ing ngasepi,

Sinimpen telenging kalbu,

Pambukaning warana,

Tarlen saking liyep layaping aluyup,

Pindha pesating sumpena,

Sumusuping rasa jati

Terjemahan:

Tidak lah samar sukma menyatu

meresap terpatri dalam keheningan semadi,

Diendapkan dalam lubuk hati

menjadi pembuka tabir,

berawal dari keadaan antara sadar dan tiada

Seperti terlepasnya mimpi

Merasuknya rasa yang sejati

Apabila sudah sampai di tataran itu, berarti kita sudah memasuki pintu gerbang, disarankan jangan berhenti disitu, tetapi lanjutkan terus hingga mencapai tataran yang tertinggi, yaitu anggambuh dengan Hyang Wisesa. Prilaku itu harus sering dilakukan dengan disiplin. Semestinya tanpa diulaspun, asalkan ajeg, dengan tata, titi, teliti, telaten nganti atul, setelah tahapan ini dicapai maka akan bisa mencapai alam selanjutnya. Sehingga perlu di gambarkan atau di ulaspun, para pembaca yang baru mulai belajar Semedi bisa merasakan kondisi-kondisi yang akan tergambarkan di sini. Segala apa yang di gambarkan di sini, inipun hanya sebatas pemahaman penulis, karena alam-alam yang akan penulis urai dan ulas ini sangatlah sulit untuk di gambarkan dengan kata-kata, jadi sekali lagi, ini hanya sebatas gambaran, yang mana tetap nantinya para pelajar yang baru mulai belajar Semedi harus mengalaminya sendiri. Dan memang harus begitu, karena itulah maksudnya bahwa laku Semedi baru dikatakan berhasil jika dilakukan praktik langsung, guna membuktikan sendiri dan menceritakan sendiri pengalaman semedi itu yang masing-masing akan memiliki makna dan arti yang berbeda.

\subsection{Manfaat Laku Semedi}

Sebagai prilaku yang utama dalam olah kebatinan, maka laku Semedi ini hendaknya diketahui apa manfaat dan kegunaannya. Adapun kegunaan dari laku Semedi diantaranya yaitu; 
1. Keadaan hati dan pikiran kita dapat menjadi jernih, sehingga setiap kita akan melangkah atau bertindak, jika sebelumnya di awali dengan samadhi, hasilnya pasti akan jauh lebih baik.

2. Meruhi Sangkan Paraning Dumadi, mengetahui kemana kelak kita akan kembali, sehingga, kelak pada saat kita harus 'pulang', kita sudah tidak kaget lagi karena sudah sering melewatinya melalui samadi yang sering kita lakukan selama kita masih hidup di dunia.

3. Ngupadi kasampurnaning gesang. Mencari kesempurnaan hidup, lahir maupun batin. Jika sampai kita kanugrahan dalam samadhi kita dan kita bisa mardhika serta nunggil denganNYA, kita akan tahu, tugas-tugas maupun hutang piutang yang belum kita selesaikan di kehidupan sebelumnya, sehingga kita bisa menggenapinya di kehidupan ini agar tidak berhutang lagi.

\subsection{Puncak Kesadaran Diri Pribadi}

Sebagai pintu menuju Kesadaran ini yang saya maksudkan di sini adalah liyep layaping aluyup seperti kutipan teks Weda Tama diatas bahwa kondiri ini yang sangat ditunggu tunggu bagi yang berolah Semedi. Pencapaian itu bukanlah hal yang sepele, namun itu adalah merupakan salah satu anugerah terindah bagi kita para pelaku olah batin, olah samadhi, yang mempunyai kegunaan yang tidak sedikit, oleh karenanya janganlah di sepelekan agar kita tidak antuk siku dari Hyang Murbeng Gesang. Kegunaannya salah satunya adalah dengan tercapainya 'pintu gerbang' tersebut, berarti kita tinggal melanjutkan perjalanan selanjutnya yang juga tidak kalah sulitnya, seperti yang akan saya gambarkan di sini. Sampai di gerbang tersebut, berarti perjalanan kita sudah benar dan tepat. Sampai di liyep layaping aluyup tersebut, jika hanya ingin menjadi seorang paranormal, sahabat sekalian berarti sudah mendapatkannya, namun secara tegas saya menyatakan bahwa saya tidak menyarankan untuk itu, karena dengan kita senang dengan hal itu, berhenti disitu, itu justru akan menghambat proses perjalanan kita selanjutnya. Setelah liyep layaping aluyup, kita harus terus melanjutkan perjalanan. Tetap seperti di awal mula kita mulai, aja nduweni penganggep, aja nduweni pengarep-arep, aja kagetan, aja gumunan.

Pandangan mata tetap ke pucuking grana, dan tetap rambatan tali keluar masuknya nafas, artinya, tetap merasakan keluar masuknya nafas. Sesudah itu keadaan semakin lama semakin luyut, seperti ngantuk dan ngelangut, namun jangan sampai tertidur, karena begitu kita tertidur, berarti kita harus mengulang dari awal lagi. Selanjutnya, semakin lama akan semakin luyut lagi, semakin ngelangut lagi, hingga suatu ketika kita seakan terlupa bahwa kita tengah berada di suatu tempat dan tengah bersamadhi, kitapun juga tidak terasa lagi bahwa kita masih bernafas. Kita seakan terlupa akan semua hal itu. Saat itu yang kita ingat dan memang harus 
selalu kita ingat dari awal, adalah manembah kepadaNYA. Sampai di sini, kita telah menginjak ke satu alam di atasnya lagi.

Sampai di sini, kita harus semakin sareh, semakin sabar, jangan tergesa-gesa, tetap pasrah, sumarah, dan sekali lagi tetap harus awas emut, tetep juga aja kagetan, aja gumunan, aja duweni penganggep, aja duweni pengarep-arep. Sedikit saja muncul keinginan akan sesuatu, sedikit saja nduweni penganggep dan lain sebagainya tadi, kita akan gagal dan kembali harus mengulang dari awal lagi. Namun, jika kita berhasil melewati kesemua hal itu tadi, disitu kita akan bertemu dengan sosok yang wajahnya seperti wajah kita, atau yang sering di sebut sebagai Sang Pribadi / Diri Pribadi. Demikian Puncak dari laku Semedi bagi penganut Kebatinan Kejawen.

\subsection{Keadaan Jagad Agung Ginulung Lan Jagad Alit}

Untuk sampai pada tahap tersebut, semestinya sudah tidak ada yang perlu saya gambarkan lagi. Sampai pada tahap itu, apa yang ingin kita ketahui bisa terjawab secara jauh lebih gamblang lagi jika dibandingkan dengan tahap sebelumnya, yaitu tahap liyep layaping aluyup. Namun saya tetap menganjurkan, untuk terus melangkah, terus melanjutkan perjalanan batin kita, hingga suatu saat, kita akan mencapai suatu keadaan dimana Jagad Agung ginulung lan jagad alit. Guna mencapai keadaan itu, keadaan dimana Jagad Agung Ginulung lan Jagad Alit, hanya kewaspadaan kita yang bisa kita andalkan, hanya Sang Diri Pribadi kita yang bisa kita andalkan. Tanpa kewaspadaan kita, tanpa awas emut, kita tidak akan bisa awor, manunggal, anggambuh mring Hyang Widhi Wasa.

\section{Pentingya Bagi Pemangku}

Melalui Semedi sangat memiliki nilai guna bagi manggala umat terutama Pemangku dan Pinandhita. Adapu nilai Guna dari Laku Semedi yang utama diantaranya sebagai berikut:

1. Mampu menjaga Diri Pribadinya

Sebagai manusia yang memiliki Titipan Atma atau Diri Pribadi, maka anugerah itu perlu dijaga melalui Laku Semedi, karena kalau bukan badan yang berpribadi itu sendiri yang menjaga tidak ada orang lain yang lebih tahu pertama kapan bahaya itu datang.

2. Dapat digunakan Menjaga Umatnya

Pemangku dan Pinandhita adalah Manggala atau Pemimpin terdepan dalam menjaga Umatnya, maka jika sudah mampu menjaga Dirinya, melalui Laku Semedi dapat digunakan untuk menyengker Umatnya agar terlindung dari Mara yang selalu datang tanpa permisi.

3. Untuk Mencapai Kalepasan 
Kalepasan merupakan bahasa Jawa Kuno yaitu kebebasan (dari ikatan keduniawian, dari kelahiran kembali). Mulder (1995: 589) menyebutkan bahwa kalepasan merupakan suatu jalan pembebasan bagi atma yang mempribadi untuk memperoleh tujuan yang tertinggi yaitu moksa. Kalepasan dicapai dengan melaksanakan yoga, yaitu terpisahnya antara pikiran dan jasmani. Pikiran harus dikendalikan karena pikiran yang selalu melayang-layang kemana-mana yang mengakibatkan orang cenderung pada obyek-obyek keduniawian.

Poespoprodjo (1991) dalam bukunya 'Logika Scientifika' Ia mambagi cara berpikir yang baik, logis-dialektis. Mencintai kebenaran adalah bagian berpikir yang baik. Wujud dari kebenaran adalah kerajinan, kejujuran, siap menerima kebenaran walaupun berlawanan dengan prasangka maupun pengolongan. Dalam pencarian kebenaran ini merupakan unsur instrinsik setiap manusia. Untuk mencapai kebenaran harus melalui berbagai langkah-langkah dan kegiatan yang amat penting supaya kita dapat melaksanakan kebenaran dengan tepat dan seksama. Mencintai cara berfikir yang terang, jelas, tajam membeda-bedakan antara yang baik dan benar. Dalam berpikir agar terjadi kebenaran hendaknya tidak mudah membuat suatu kesimpulan jika kurang bukti pendukung. Sedangkan berpikir dalam praktek hendaknya cakap dan cekatan sesuai prinsip dan hukum, sanggup mengenali jenis-jenis, nama-nama, sebab kesalahan berpikir. Dengan berpegang pada tataran berpikir demikian, akan dapat menghantarkan pikiran seseorang kedalam penetuan pilihan-pilihan yang tepat, sesuai dengan penelitian ini yaitu cara-cara memikirkan bagaimana dapat mempersatukan Diri dan Tuhan sesuai petunjuk yang benar, sehingga tidak tersesat.

Dalam Lontar Wrhaspati Tattwa mengambarkan tentang adanya bagian tubuh manusia yang dominan atau memiliki tiga sifat guna yaitu Tri Guna Tattwa yang terdiri dari sattwam, rajah, tamas. Pikiran yang serba ringan dan jernih disebut pikiran sattwa, pikiran yang cepat gerakan dinamakan pikiran rajah, pikiran yang gelap-gelap itu dinamakan pikiran tamas. Pikiran juga yang menyebabkan atma menikmati sorga. Pikiran juga yang menyebabkan atma jatuh ke neraka. Pikiran yang menyebabkan lahir sebagai manusia. Pikiran juga yang menyebabkan atma mencapai moksa dan kelepasan. Digambarkan juga tentang ciri-ciri pikiran itu bahwa jika prilaku manusia itu sungguh-sungguh jujur, mengetahui perbedaan antara sesuatu dan batasbatasnya, memahami Iswara Tattwa, pandai, manis tutur katanya, indah badanya adalah ciri pikiran satwika. Pikiran bengis, pemarah dan menakutkan, congkak, suka memperkosa, panas hati, loba, melakukan perbuatan kasar dengan tangan, kaki, berkata kasar, tidak rasa kasih, kurang waspada dan suka mengatasi adalah ciri pikiran Rajah. Pikiran yang dihadapi oleh rasa takut, payah, kotor, mabuk, suka tidur, suka memfitnah, suka membunuh, kurang periksa, keruh hati, pandangan berat adalah ciri pikiran yang tamah. Sattwa, Rajah, Tamah dikatakan 
membelenggu manusia. Apabila satwika pikiran itu menyebabkan atma mencapai moksa, karena atma suci murni, melaksanakan rasa agama dan petuah guru. Apabila sattwam dan rajas sama besarnya itu sebabnya ingin melaksanakan dharma dan berhasil dharma itu dilaksanakan olehnya berdua menyebabkan atma berpulang kesorga, sebab sattwa itu ingin berbuat kebaikan dan rajas yang melaksanakan. Apabila ketiganya sama besarnya baik sattwa, rajas, dan tamas itu menyebabkan terlahirnya menjadi manusia, karena ketigannya sama-sama terpenuhi keinginannya.

Menurut Swamiprabhupada bahwa pikiran dapat diumpamakan sebagai pohon. Ada angin atau tidak daun pipal selalu bergetar. Demikian pula pikiran selalu berubah dan mudah terombang-ambing. Disamping itu pikiran sangat kuat dan keras kepala. Misalkan saja gajah, binatang ini juga sangat kuat dan kadang-kadang amat galak. Namun dengan tongkat yang berujung runcing engkau dapat mengasainya. Kuda tidak pernah diam, itulah sebabnya ia dinamakan ashok yang artinya bergerak terus, ia selalu mengerakkan kakinya, telinganya, kepalanya, atau ekornya. Karena ingin bergerak terus, ia berjalan kian kemari, tetapi dengan tali kekang ia dapat dikendalikan dan diarahkan sesuai dengan kehendak sang penunggang. Contoh lain seperti kera yang suka berkelana kian kemari mencerminkan ketidak tenangan dan ketidak tetapan; tetapi dengan latihan, iapun dapat dikendalikan. Karena itu sebagai halnya dengan tongkat engkau dapat mengendalikan gajah dan dengan kendali engkau dapat mengendalikan kuda demikian juga dengan latihan engkau dapat mengendalikan kera yang tak mau diam itu, demikian pula dengan pikiran yang kuat dan tidak tetap, dapat dikendalikan dengan ketidak terikatan dan latihan terus menerus dengan kata lain vairagya.

Ketidakterikatan berarti menyadari sifat benda-benda yang sementara dan tidak membiarkan pikiran dan perasaan terikat pada hal-hal yang fana ini. Ini tidak berarti bahwa engkau tidak terikat padanya. Tidak mungkin bahwa kita samasekali tidak acuh pada bendabenda duniawi. Namun, engkau dapat meniadakan rasa milikku, rasa memiliki. Bila engkau sudah menghilangkan rasa memiliki itu, engkau dapat maju terus dan dapat menikmati berbagai macam benda duniawi, hal itu tidak akan membahayakan. Dalam dunia yang fana ini segala sesuatu, setiap orang, dan semua benda mengalami perubahan. Dunia memiliki tiga macam perubahan, tumbuh, hidup, dan mati. Semua benda tunduk pada perubahan ini. Jika engkau menghayal bahwa dunia yang bersifat sementara dan tidak langgeng ini adalah abadi, dan engkau terikat pada benda-benda yang ada didalamnya, itu sungguh-sungguh pikiran sinting.

Begitu sulitnya menurut pandangan dalam pemahaman tentang pikiran itu akan tetapi ada beberapa kiat yang dapat dijadikan untuk mengendalikan pikiran itu diantaranya adalah dengan mengolah diri pada pemahaman kebatinan. Selain itu masih ada beberapa hal yang dapat 
dijadikan sebagai pengendali pikiran yaitu Vairagya dengan latihan dan ketidakterikatan pikiran dapat dikendalikan. Latihan yang dimaksud menurut ajaran ini adalah dengan latihan kesadaran akan Tuhan bersemayam dalam diri, sehingga seseorang akan dibawa dengan bentuk kesibukan jenis bhakti pada Tuhan. Kesibukan yang paling utama adalah dengan smaranam atau mengidungkan nama Tuhan. Mengenang selalu atau eling, ingat pada Tuhan dalam setiap saat adalah cara rohani yang sangat kuat untuk menghilangkan segala keragu-raguan dari pikiran. semakin seseorang eling pada Gusti atau Tuhan, makin ia dibebaskan dari kebodohan dan ikatan terhadap sesuatu yang menarik pikiran menjauh dari Tuhan. Dengan melepaskan ikatan antara pikiran dan kegiatan yang tidak dipersembahkan kepada Tuhan, dengan mudah sekali seseorang mempelajari Vairagya. Vairagya berarti ketidak terikatan_dengan alam dan kesibukan pikiran dalam kerohanian. Ketidakterikatan rohani yang tidak mengakui bentuk pribadi Tuhan lebih sulit daripada mengikat pikiran dalam kegiatan Krsna. Mengikatkan pikiran pada kegiatan Krsna sangat praktis, sebab kalau seseorang mendengar tentang Krsna, dengan sendirinya ia terikat kepada Roh Yang Paling Utama. Ikatan ini disebut paresanubhuti, yang berarti kepuasan rohani. Hal ini seperti rasa puas dalam hati seseorang yang lapar terhadap setiap suap makanan yang dicicipinya. Kalau orang lapar makin banyak yang dimakannya, makin ia merasa puas dan kuat. Begitu pula dengan melaksanakan Bhakti, seseorang merasakan kepuasan rohani selama pikirannya menjadi semakin lepas dari ikatan terhadap tujuan-tujuan material.

Konsep manunggaling kawulo-Gusti juga bisa dilihat dalam cerita Dewaruci. Menurut Endraswara (2003) dalam bukunya 'Falsafah Hidup Jawa' bahwa agar manusia bisa manunggal hendaknya ia tahu asal dan tujuan hidupnya. Tujuan hidup adalah bersatu (manunggal) dengan Tuhan. Agar bisa bersatu dengan Tuhan, manusia harus berbekal ngelmu rasa yaitu hendaknya manusia rela terhadap takdir suci, rela terhadap dzikir dalam hening, dan rela terhadap anasir. Maksudnya bahwa manusia hendaknya ikhlas terhadap takdir dari awal sampai akhir dalam permohonannya. Dalam dzikir hendaknya ada suasana keheningan agar bisa menyatu dengan AlKhalik atau jumbuhing kawulo-Gusti sedangkan anasir adalah percaya adanya asal-usul kehidupan atau sangkan paraning dumadi.

Kesempurnaan adalah kondisi dari pikiran yang tidak tergantung pada perubahan waktu dan tempat. Moksa atau Mukti, sebagai tujuan akhir dari kehidupan maya di alam kematian (mrtyuloka) ini, sering disalah tafsirkan oleh kebanyakan orang sebagai suatu keadaan, dimana jasad seseorang lenyap pada saat ia meninggal, hal ini tidaklah demikian, karena menurut yogawasistha, moksa adalah pencapaian inti kebahagiaan Brahman, melalui pengetahuan tentang sang Diri. 
Moksa merupakan pembebasan dari siklus kelahiran dan kematian, karena tanpa adanya kelahiran tidaklah mungkin akan ada kematian. Kelahiran itu sendiri timbul akibat adanya Vasana dan Sankalpa, yaitu kesan yang membekas dari pemikiran karma, sedangkan dalam moksa, pikiran telah mencapai ketenangan. Jumlah kenikmatan diseluruh alam semesta ini hanyalah setitik saja jika dibandingkan dengan kebahagiaan Moksa, karena yang disebut moksa itu bukan hanya terjadi di Dewataloka (alam para dewa), patala ataupun di dunia manusia ini. Apabila segala keinginan termusnahkan, maka pemadaman gejolak pikiran itu sendiri merupakan Moksa.

Moksa tidak memiliki ruang dan waktu, bahkan tidak memandang keadaan diluar maupun didalam. Apabila pikiran khayal tentang 'Aku' atau ahankara lenyap, maka akhir dari pemikiran yang merupakan maya, disebut juga sebagai Moksa. Sankalpa hanyalah menimbulkan samsara, sedangkan penghancuran sankalpa adalah moksa. Moksa merupakan keterbebasan dari segala macam penderitaan dan pencapaian kebahagiaan tertinggi. Kelahiran dan kematian menimbulkan penderitaan yang berat, sehingga keterbebasan dari kelahiran dan kematian merupakan keterbebasan dari segala macam penderitaan.

Moksa selagi kita menjalani kehidupan didunia ini disebut Jivan Mukti. Untuk mendapatkan Jivan Mukti ada berbagai syarat yang harus dipenuhi diantaranya; Nityanitya Vastuviveka (kemampuan pembeda antara yang abadi dan yang sementara), Ihamutrartha Phala Bhoga viraga yaitu tidak memperdulikan kenikmatan dalam kehidupan ini atau dalam kehidupan surgawi dan terhadap hasil perbuatanya, dan sebagainya. Jivan Mukti merupakan tahap awal menuju ke tahap berikutnya yang disebut Videha Mukti, yaitu tahapan Moksa dimana sang Diri sudah tidak memerlukan badan jasmani lagi.

Moksa menurut Titib (2006) bahwa tiada keterikatan atma dan bersatu dengan Brahman. Dilihat dari kondisi atma saat bersatu dengan Brahman, Titib mengutip dari Radhakrishnan, dapat dibedakan menjadi empat jenis moksa yaitu samipya adalah kemiripan dengan sifat Tuhan, sarupya atau sadharmya, kesamaan sifat Tuhan dan mencerminkan sifat keagungan-Nya, Salokya atau keberadaan berdampingan yang sadar dengan Tuhan dalam dunia yang sama dan Sayujya atau bersama dengan Tuhan mendekati kemanunggalan.

Sedangkan Moksa menurut Veda, masih dalam Titib, bahwa orang yang telah mencapai moksa jauh dari kegelapan, memperoleh kebahagiaan tertinggi, keabadian dan bebas dari ikatan berulang-ulang kutipan dari Yajurveda XXXI. 18. dalam upanisad disebutkan bahwa moksa (kalepasan) berarti pencapaian kebebasan dari ikatan duniawi, bebas dari karmaphala (hasil perbuatan) dan punarbhawa (kelahiran kembali) 
Ada tiga tingkatan moksa menurut orang yang melihat kebenaran (Titib, 2006) yaitu pertama adalah kalepasan dari keterikatan ajnana (kebodohan). Kedua adalah keselamatan lepas dari ragasamkyasa (hancurnya keterikatan yang sangat mendalam/kemelekata). Ketiga adalah trsnaksaya (menghancurkan kehausan seperti sangat terikat dengan keduniawian/kemelekatan indrawi. Demikian dipaparkan oleh Prof. I Made Titib, P.hD dalam bukunya Svarga, Naraka Moksa dalam Svargarohanaparva.

Sudiana dan Artha (2007) menuliskan bahwa cara mencapai Moksa dengan jalan berbakti kepada Dharma dalam arti seluas-luasnya. Catur Yoga disebutkan sebagai suatu bagian dari jalan menuju Moksa. Bagian dari Catur Yoga diantaranya Bhaktiyoga artinya melakukan kebaktian yang tulus secara terus menerus. Karmayoga artinya melakukan perbuatan-perbuatan mulia dan bermanfaat tanpa pamerih. Jnanayoga artinya mengabdikan pengetahuan dan Rajayoga yaitu melakukan tapa, brata, yoga dan semadhi (raja) secara benar. Keempat Yoga itu jika ditekuni dan dilaksanakan dengan benar, masing-masing akan menghantarkan pada salah satu bagian jalan menuju pembebasan atma dari kesengsaraan menuju Moksa.

Setelah terlatih dengan Laku Semedi, maka adakalanya saat tertentu ketika menemukan tanda-tanda kematian, maka perlu kiranya mempersiapkan langkah-langkah menuju Kalepasan. Adapun tanda dari kematian yang perlu diwaspadai diantaranya sebagai berikut:

1. Umur lanjut yang ditandai Rambut putih,

2. Sering Sakit yang sulit disembuhkan,

3. Berkurangnya gairah hidup,

4. Mendengar Suara-Suara Gaib,

5. Mimpi yang buruk,

6. Ditangan Pencabut Nyawa.

\section{Cara mencapai kalepasan sebagai Berikut:}

Ada tiga prilaku orang yang ingin mencapai kebebasan yaitu sakala (berbadan Triguna; satwa, rajas dan tamas) kewala suddha (melepaskan diri dari kebahagiaan duniawi), dan malinatwa (tak ternoda oleh keterikatan duniawi di anggap Siwa Suci). Selanjutnya ada tiga sarana agar orang mencapai kebahagiaan bathin yaitu Wairagyaditraya (memiliki pengetahuan tinggi), Pararogya (meninggalkan keterikatan duniawi), Dhyanaditraya (pemusatan pikiran/samadi dengan melakukan pranayama secara teratur). Selanjutnya jalan kalepasan terdiri dari sembilan dan kesepuluh, jika melalui kesembilan jalan maka akan terlahir lagi kedunia dan jika melalui jalan kesepuluh akan manunggal atau bersatu dengan Paramasiwa dan tidak kembali lagi kedunia. Pada bagian ini lebih menekankan agar diketahui akibat adanya berbagai 
macam kelahiran mahkluk di dunia ini, baik tumbuhan, hewan dan terlebih manusia. Dengan demikian sudah dapat memberikan jawaban adanya reinkarnasi/punarbhawa.

Ada Tiga Sarana Utama bagi orang yang mengutamakan kebebasan batin dimana sarana itu dapat mengantar kepada sesuatu keberhasilan. Ketiga sarana dimaksud adalah; Wairagyaditraya, Pararogya, dan Dhyanaditraya. Wairagyaditraya adalah mengadakan bahyawairagya parawairagya, Iswarapranidhana. Bahyawairagya artinya Kawiratin. Kawiratin artinya Pendeta yang berilmu tinggi dimasyarakat. Parawairagya adalah Pendeta witaraga. Pendeta Witaraga adalah pendeta yang meninggalkan kesenangan hidup (keduniawian). Iswarapranidhana artinya Sang pendeta yang taat yogaprawrtti. Yogaprawrtti artinya pendeta yang taat melaksanakan pemujaan kepada Tuhan. Dhyanaditraya artinya melakukan pranayama, dharana dan Samadhi. Pranayama artinya pemusatan dan pengaturan nafas. Dharana adalah pranawajnana artinya pemusatan batin. Samadhi adalah nirhyaparajnana yang artinya ingat pada tuntunan yang tampak. Itulah sarana untuk menemukan Sanghyang Bhedajnana (Ganapati Tattwa. Sloka. 44 halaman 43-44). Yang perlu diperhatikan Saat Menuju Kematian:

Mwah yan katekan ing kapatin, aja tan karasanana lunga nira, sanghyang Siwatma sah saking sarira, aja weha dalan ana babahan sanga, ndya ta ngaran babahan sanga; ring luhur 7, ring sor 2. kanistha dalan ika nga. Yan adalan ring siwadwara Madhya nga, kunang ikang marga uttama, dalan ira sanghyang Siwatma, ring tungtung ing sabda, selaning hidep nga ri kaketeg, yan teka ring kalepasan, aja ngangen sarira dewek, mwang anak rabi mwah kasukhan, ikang tiga atemah siji, ya ta tutakena marga tungtung ning sabda, selaning hidep. Iti kalepasan sang bhujanggasiwa, haywa wera rahasya dahat, tan siddha phalanya (Ganapati Tattwa. Sloka. 51-53. bagian 5 halaman 20-21)

Terjemahan:

Jika tiba saatnya kematian, janganlah tiada dirasakan kepergian Sang Roh Yang Mempribradi tatkala terpisah dari Sang Diri. Janganlah Sang Roh diberi jalan keluar melalui 9 lubang. Mana yang disebut 9 lubang antara lain; diatas ada 7 jalan (mata $=2$, telinga $=2$, hidung $=2$, mulut $=1$ ). Dibawah ada 2 jalan (kemaluan $=1$, dubur $=1$ ). Kesembilan jalan itu disebut nista. Apabila sang Roh meninggalkan Sang Diri melalui Siwadwara (ubun-ubun) disebut jalan menengah. Sedangkan jalan utama apabila Sang Roh melalui ujung suara (sabda) meninggalkan Sang Diri yaitu melalui celah-celah pikiran. Artinya pada denyutan jantung. Apabila saat terpisahnya Sang Roh dari Sang Diri janganlah pikirkan badanmu lagi, jangan ingat anak istri dan jangan pikirkan kemewahan dunia, ketiganya (Sanghyang Siwa, Sanghyang Pramana, dan Sanghyang Jnana) pusatkan jadikan satu arah, ikutilah jalan ujung suara yaitu celah-celah pikiran itu. Inilah kebebasan Sang Roh Yang Mempribadi menuju Dia Sang Roh Yang Maha Agung Sang Bujangga dan Siwa. Janganlah hal ini disebarkan, karena sangat rahasia, karena tidak akan berhasil jadinya.

Jika jalan itu tidak dipahami maka akan terjadi proses kelahiran berikutnya dengan menjelma berbagai macam penjelmaan seperti pada sloka berikut ini: 
Mwah yan amarga ring lalata dadi bhujanggadi. Yan amarga ring soca dadi ksatrya, yan amarga ring irung dadi tumenggung. Yan amarga ring karma dadi sira Demang. Yan amarga ring tutuk dadi pacahtanda. Yan amarga ring pranawayu(...), yan amarga ring Siwadwara dadi ratu anyakrawrtti, juga sarining tiga rihanaking netra unggwanya. .

Terjemahan:

Apabila saat Sang Roh meninggalkan Sang Diri melalui dahi (maka didalam penjelmaannya kemudian akan) menjadi cendekiawan utama. Apabila melalui mata akan lahir menjadi ksatria. Apabila melalui hidung akan menjadi Demang. Apabila melalui mulut ia akan lahir sebagai Panca tanda. Apabila lepas melalui aksara gaib (Om)...Dan apabila Sang Roh meninggalkan Sang Diri melalui Siwadwara maka akan lahir sebagai raja besar yang menguasai dunia (Ganapati Tattwa. Sloka. 16 halaman. 52)

\section{Mantra yang perlu diucapkan saat menuju Kalepasan:}

Om, Sang, Bang, Tang, Ang, Ing, Nang, Mang, Sing, Wang, Yang, Ang, Ung, Mang: Om,

\section{PENUTUP}

Sebagai Penganut Kebatinan terutama Pemangku dan Pinandhita, laku Semedi adalah Utama guna mencapai Kesadaran Diri. Untuk mencapai kesadaran Diri diperlukan berbagai pemahaman awal bahwa dalam diri terdapat Tiga Alam yang terdiri dari; 1) Alam Guru loka Berada di Otak. 2) Alam Indra loka Berada di Hati. 3) Alam Jana loka Berada di Kelamin. Setelah itu baru dikatakan bahwa kondisi badan sebagai Buwana Alit atau Jagad Cilik. Ada beberapa tahapan untuk mencapai puncak Semedi bagi Penganut Kebatinan Kejawen. Diantara yang menjadi kunci keberhasilannya adalah keadaan suci, tertata, konsentrasi, disiplin dan ketenangan dalam keadaan apapun. Bagi mereka yang sudah mencapai puncak Semedi maka akan menemukan jatidiri nya sendiri bahwa mampu melihat badannya sendiri. Keadaan ini memerlukan waktu yang rutin agar tercapai. Bagi penganut Kebatinan Kejawen, maka prilaku Semedi ini sebagai benteng untuk mempersiapkan kelak jika dirinya akan dipanggil kembali keasalnya sehingga tidak mengalami kegelisahaan lagi dalam menjalankan kehidupannya. Pentingnya Laku Semedi Bagi Pemangku dan Pinandhita adalah dapat digunakan untuk menjaga Diri, Menjaga Umatnya, dan yang terpenting nantinya untuk Mencapai kalepasan.

\section{DAFTAR PUSTAKA}

Chodjim, Achmad. 2016. Serat Wedhatama For Our Time. Serambi Baru.

Endraswara, Suwardi. 2003. Falsafah Hidup Jawa. Cakrawala. Tangerang.

Koentjaraningrat. 1990. Pengantar Antropologi I. Jakarta: Universitas Indonesia Press.

Maswinara, I Wayan, 1996. Konsep Panca Sraddha. Paramita. Surabaya

Punyatmadja, Oka, Ib. 1992. Panca Cradha. Upada Sastra. Denpasar. 
Poespoprodjo, W. 1991. Logika Scientifika. Pt. Remaja Rosda Karya. Bandung

Soekmono. 2017. Candi Fungsi Dan Pengertiannya. Yogyakarta. Ombak.

Soekmono, R. 2016. Pengantar Sejarah Kebudayaan Indonesia 2. Yogyakarta. Kanisius.

Soekmono, R. 2017. Pengantar Sejarah Kebudayaan Indonesia 1. Yogyakarta. Kanisius.

Sudiana, I Gst Ngurah dan Artha, I Made, 2007. Samhita Bhisama Parisada Hindu Dharma Indonesia. PHDI Propinsi Bali.

Titib, I Made, 2006. Svarga, Naraka, Moksa Dalam Svargarohanaparva. Paramita. Surabaya

Triguna, Ida Bagus Gede Yudha, 2008, Estetika Hindu Dan Pembangunan Bali. Denpasar: PT. Mabhakti.

Wirjaatmadja. 1950. “Pt. Citra Jaya Murti”. Surabaya.

Yudhi. 2012. Serat Dewaruci-Pokok Ajaran Tasawuf Jawa.yogyakarta. Narasi.

Zoetmulder, P.J. 2011. Kamus Jawa Kuno Indonesia. Jakarta. PT. Gramedia pustaka utama.

Lontar Ganapati Tattwa 